\title{
Research Article \\ High Isolation Dual-Polarized Patch Antenna with Hybrid Ring Feeding
}

\author{
Xian-Jing Lin, Ze-Ming Xie, and Pei-Sheng Zhang \\ School of Electronic and Information Engineering, South China University of Technology, Guangzhou, China \\ Correspondence should be addressed to Xian-Jing Lin; eexjlin@mail.scut.edu.cn
}

Received 11 January 2017; Revised 24 February 2017; Accepted 11 April 2017; Published 3 May 2017

Academic Editor: Paolo Baccarelli

Copyright (C) 2017 Xian-Jing Lin et al. This is an open access article distributed under the Creative Commons Attribution License, which permits unrestricted use, distribution, and reproduction in any medium, provided the original work is properly cited.

\begin{abstract}
This paper presents a hybrid ring feeding dual-polarized patch antenna with high isolation in a wide working band. The proposed antenna consists of a circular radiating patch printed on the upper horizontal substrate, two pairs of $\Gamma$ shaped strips printed on two vertical substrates, and a hybrid ring feeding network printed on the lower two horizontal substrates. The proposed antenna adopts $\Gamma$ shape strips coupled feeding structure to achieve a wide operating band. Furthermore, a hybrid ring feeding structure with high isolation in a wide bandwidth, which is firstly proposed, is applied as feeding network. When one port is excited, the feeding network can realize twice the power cancellation. Thus, high ports isolation characteristics can be obtained. A prototype of the proposed antenna is fabricated and measured. Measured results show that the $10 \mathrm{~dB}$ reflection coefficient bandwidths of the two ports are both about $38.7 \%$, with port isolation higher than $40 \mathrm{~dB}$ through most of the band, and the cross-polarizations are below $-24 \mathrm{~dB}$.
\end{abstract}

\section{Introduction}

With the rapid development of wireless communication systems, the demand for dual-polarized patch antennas with broadband, low cross-polarization, and high port-to-port isolation has been gradually growing. Lots of studies on improving the performances in theses domains of dualpolarized patch antennas have been reported. Aperture coupled technique is the most commonly used technique in designing dual-polarized patch antennas $[1,2]$. However, in order to avoid intersection of slots, sizes of the slots are highly restricted. As a result, the bandwidth of these kinds of antennas is difficult to widen. Hybrid feeding structure is a good method to achieve high ports isolation [3]. However, the uniformity of the ports with different polarizations is difficult to be optimized, which may easily cause different circuital and radiating characteristics of the two different polarizations. The magnetic loop feeding dual-polarized patch antenna for bandwidth and isolation enhancement is reported in [4]. The ports isolation is about $40 \mathrm{~dB}$ over a $38 \%$ impedance bandwidth. However, the asymmetric feeding structures will lead to different performances from the two ports. The dualpolarized patch antennas applying probe director or coupled feeding have a limited impedance bandwidth or high crosspolarization [5-7]. The flexible coaxial cables directly feeding technique is used in $[8,9]$ to improve the isolation and crosspolarization, but the antennas are relatively high. Differential feeding for dual-polarized patch antennas design can help to decrease cross-polarization and increase port-to-port isolation $[10,11]$. However, the antennas have narrow impedance bandwidth. Recently, a dual-polarized patch antenna fed by a wide balun can realize wide working band, low cross-polarization, and high isolation performances [12].

In this paper, a dual-polarized patch antenna fed by a hybrid ring structure is proposed. The proposed antenna adopts $\Gamma$ shape strips coupled feeding structure [13] to achieve wide working band. And a novel hybrid ring is applied as a feeding network. The hybrid ring feeding network has a broadband high isolation characteristic. The hybrid ring feeding structure consists of eight $\lambda / 4$ lines and two orthogonaloffset differential feeding lines for two polarizations. And the hybrid ring feeding structure can realize twice the power cancellation to the other port when one port is excited. Thus, the ports isolation within a wide bandwidth is highly enhanced. Moreover, due to the differential feeding and fully symmetric structure, low cross-polarization level can 


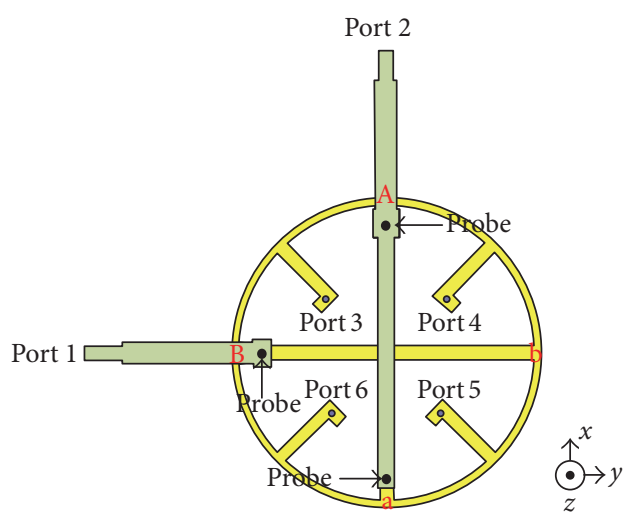

FIGURE 1: Layout of the hybrid feeding network.

be obtained. The proposed dual-polarized patch antenna has good performances of broad impedance bandwidth, high isolation, and low cross-polarization level.

\section{Geometry and Design of the Antenna}

2.1. Hybrid Ring Feeding Structure. The hybrid ring feeding network is shown in Figure 1. It is a ring which is composed of eight $\lambda / 4$ lines and two orthogonal-offset differential feeding lines, where $\lambda$ is the guided wavelength of the center frequency. The two differential feeding lines are printed on two different substrates to avoid intersection. The quarterwavelength impedance transformer line and differential feeding line of Port 2 and the quarter-wavelength impedance transformer of Port 1 in green are printed on the top of the upper substrate, and the differential feeding lines of Port 1 and eight $\lambda / 4$ lines of the ring in yellow are printed on the bottom face of the lower substrate. The feeding lines printed on different substrates connect to each other via three probes. The ground plane is arranged between the two substrates. The differential feeding line of Port 1 consists of a power divider and a half-wavelength delay line. And a quarter-wavelength impedance transformer is used to achieve good impedance match. An equivalent structure of the hybrid ring feeding network is illustrated in Figure 2. The working principle of the hybrid feeding network is analytically and numerically analyzed as follows: the impedances of Ports 3-6 and the halfwavelength delay lines are $Z_{0}$. The characteristic impedance of each $\lambda / 4$ microstrip line of the hybrid ring is $\sqrt{2} Z_{0}$, and the impedance of each $\lambda / 4$ impedance transformer is $\sqrt{2} Z_{0} / 2$. When Port 1 is excited, signals are split into two equal and out-of-phase components at points $\mathrm{B}$ and $\mathrm{b}$, and the voltage at the "A-a" plane of the feeding work is zero and shorted. The equivalent circuit can be simplified as in Figure 3.

According to Figure 3, it can be derived that the output impedance of point $B$ is decided by the shunt branches of "Port 3-B," "Port 6-B," and "b-B." As the impedance of Port 3 is $Z_{0}$, after the $\lambda / 4$ impedance transformer, the impedance becomes $2 Z_{0}$, and so does the branch of "Port 6-B." The branches of "Port 4-b" and "Port 5-b" are the same as branches of "Port 3-B" and "Port 6-B," so the output impedance

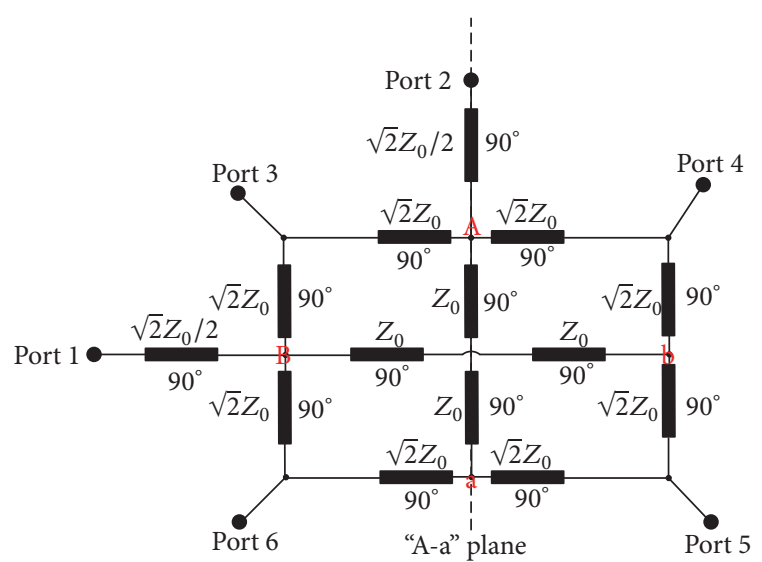

Figure 2: Equivalent structure of the hybrid feeding network.

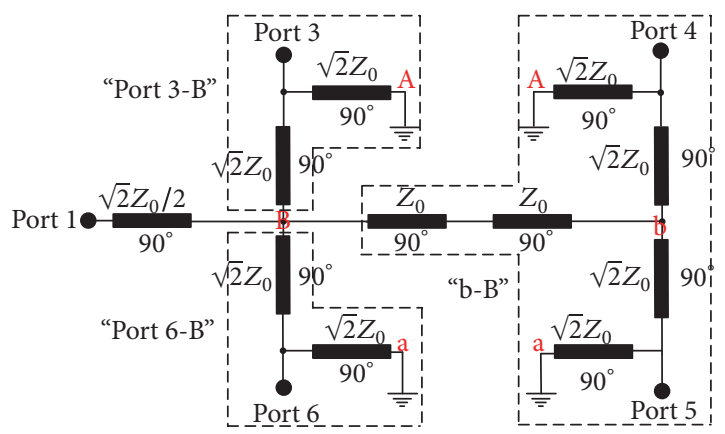

FIGURE 3: Equivalent structure of the hybrid feeding network with Port 1 excited.

of point $\mathrm{b}$ is $Z_{0}$; after the $\lambda / 2$ impedance transformer, the impedance keeps unchanged. Consequently, the impedances of shunt branches of "Port 3-B," "Port 6-B," and " $\mathrm{b}-\mathrm{B}$ " are $2 Z_{0}, 2 Z_{0}$, and $Z_{0}$, respectively. Then, the output impedance of point $\mathrm{B}$ is $Z_{0} / 2$; after the $\lambda / 4$ impedance transformer, the impedance of Port 1 becomes $Z_{0}$. With Port 2 excitation, the "B-b" plane of the feeding work is then shorted. The impedance of Port 2 is also $Z_{0}$. When $Z_{0}$ is equal to $50 \Omega$ and the center frequency is $2.3 \mathrm{GHz}$, the simulated $S$-parameters of the hybrid feeding network are shown in Figure 4. It can be seen that a very deep transmission zero is located at the center frequency. The deep transmission zero is produced by twice the power cancellation. When Port 1 is excited, signals will firstly cancel at point $B$ and point $b$. Additionally, a halfwavelength delay line is employed between point $A$ and point a, and the signals will cancel again. Moreover, the signals from Port 1 are equally split to Ports 3-6, wherein Ports 3 and 6 are with in-phase signals, as well as Ports 4 and 5. However, the two pairs of ports are with out-of-phase signals, while, with Port 2 excitation, the signals from Port 2 will also be equally split to Ports 3-6. Then, Ports 3 and 4 are with in-phase signals, as well as Ports 5 and 6 . Ports 3 and 4 and Ports 5 and 6 are then two pairs of out-of-phase ports. Figure 5 shows the simulated $S$-parameters of the hybrid feeding network with different half-wavelength delay lines of Port 1 and Port 2. It is clearly seen that the isolated bandwidth of the hybrid feeding 


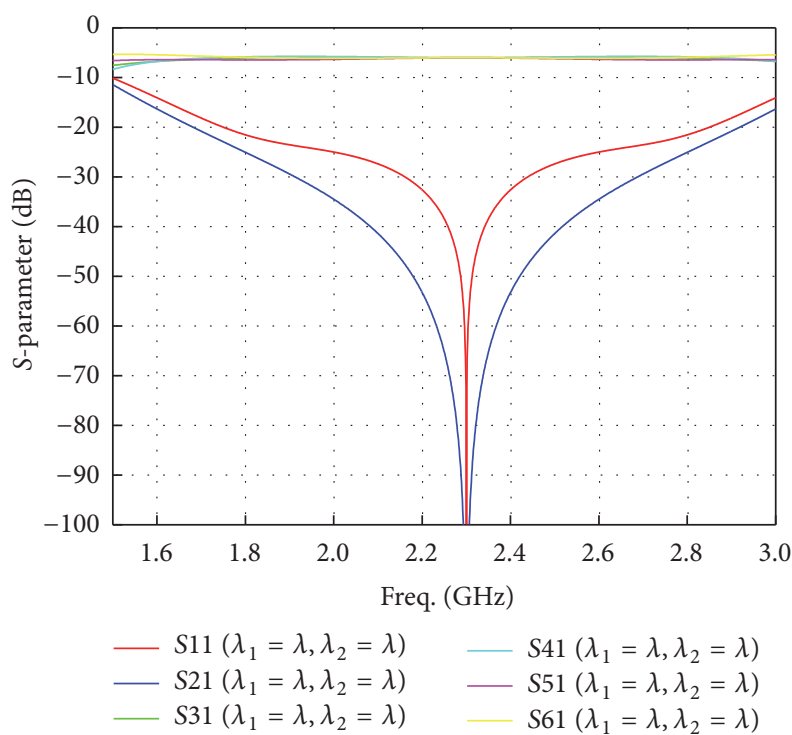

FIGURE 4: $S$-parameters of the hybrid feeding network with equal half-wavelength delay lines of Port 1 and Port 2.

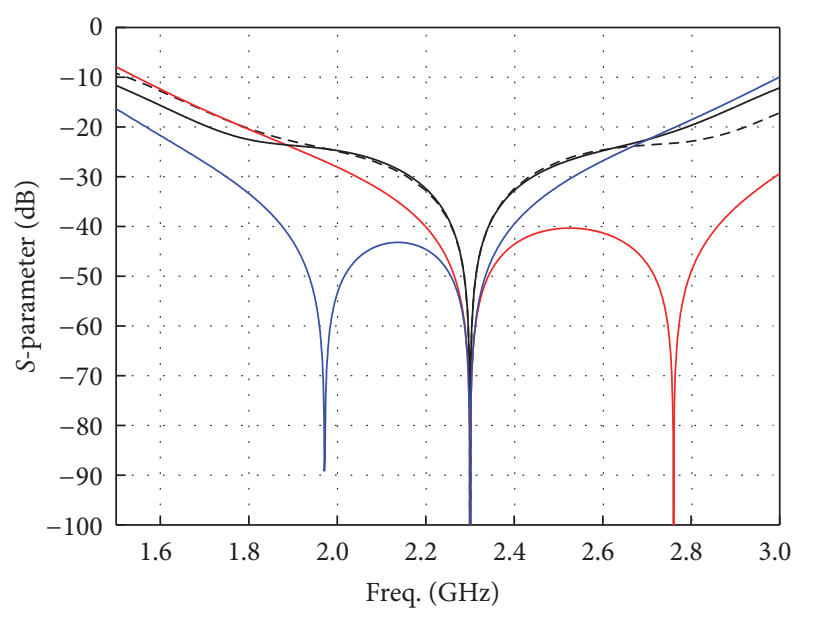

$$
\begin{array}{r}
S 11\left(\lambda_{1}=\lambda, \lambda_{2}>\lambda\right)-S 21\left(\lambda_{1}=\lambda, \lambda_{2}<\lambda\right) \\
--S 11\left(\lambda_{1}=\lambda, \lambda_{2}<\lambda\right)-S 21\left(\lambda_{1}=\lambda, \lambda_{2}>\lambda\right)
\end{array}
$$

FIGURE 5: $S$-parameters of the hybrid feeding network with different half-wavelength delay lines of Port 1 and Port 2.

network can be tuned by changing the operating frequencies of half-wavelength delay lines of Port 1 and Port 2 . When $\lambda_{1}=$ $\lambda, \lambda_{2}<\lambda$ or $\lambda_{1}=\lambda, \lambda_{2}>\lambda$ ( $\lambda_{1}$ is the wavelengths of halfwavelength delay lines of Port $1 ; \lambda_{2}$ is the one of Port 2), the transmission zero produced by the half-wavelength delay line of Port 2 will shift to the higher frequency or lower frequency, and the zero produced by the half-wavelength delay line of Port 1 is unchanged. When $\lambda_{1} \neq \lambda, \lambda_{2}=\lambda$, the zero produced by the half-wavelength delay line of Port 1 will also shift. Based on the above analysis, we can know that the hybrid feeding network can realize good impedance matching and high ports isolation in a wide operating band.
2.2. Antenna Design. The geometry of the proposed dualpolarized patch antenna is shown in Figure 6. It consists of five substrates: the upper horizontal substrate (\#1), the middle vertical substrates (\#2 and \#3), and the bottom horizontal substrates (\#4 and \#5). The radiating circular patch is printed on one of the horizontal substrates (\#1). The four $\Gamma$ shaped strips are printed on the vertical substrates (\#2 and \#3) and soldered to Ports 3-6 of the hybrid ring feeding network via four probes. The quarter-wavelength impedance transformer and differential feeding line of Port 2 and the quarterwavelength impedance transformer of Port 1 are printed on the top layer of the horizontal substrate (\#4), and the hybrid ring with the differential feeding line of Port 1 is printed on the bottom layer of the horizontal substrate (\#5). The ground is between the two horizontal substrates (\#4 and \#5). The height of the air layer between vertical substrates \#2 and \#3 is $18 \mathrm{~mm}$. This air layer is designed to widen the working band. All the five substrates are with dielectric constant $\varepsilon_{r}=2.55$, loss tangent $\delta=0.003$, and a thickness of $0.8 \mathrm{~mm}$. The center frequency of the proposed antenna is $2.3 \mathrm{GHz}$. The ports impedances of the hybrid ring feeding network $Z_{0}$ are $50 \Omega$. Signals from Port 1 transport along quarter-wavelength impedance transformer, and then they split into two equal and out-ofphase components by the differential feeding lines of Port 1 . The 180-degree phase shift is caused by a half-wavelength delay line. Finally, the signals transmit along Ports 3-6 to produce $y$-direction polarization, while signals from Port 2 have the same working principle and they correspond to the $x$ direction polarization. As the hybrid ring feeding network structure is fully symmetric and it can realize high ports isolation within a wide bandwidth, the proposed dual-polarized patch antenna can obtain good performances of broadband, low cross-polarization, and high isolation. The proposed antenna can be applied in radar and distributed antenna systems (DAS).

\section{Simulated and Measured Results}

For verification, a dual-polarized patch antenna is implemented and its fabrication prototype is shown in Figure 7. The simulated and measured $S$-parameters of the proposed antenna are shown in Figure 8. It can be seen that the measured $-10 \mathrm{~dB}$ fractional bandwidth of Port 1 is about $38.7 \%$, or $890 \mathrm{MHz}(1.847-2.737 \mathrm{GHz})$, corresponding to center frequency $2.3 \mathrm{GHz}$. The measured $-10 \mathrm{~dB}$ impedance bandwidth of Port 2 is $895 \mathrm{MHz}(1.875-2.77 \mathrm{GHz})$, or about $38.9 \%$. Therefore, the overlapped bandwidth of Port 1 and Port 2 is about $37.5 \%(1.875-2.737 \mathrm{GHz})$. It is also observed that the measured port-to-port isolation of most of the operating band is higher than $40 \mathrm{~dB}$. The isolation bandwidth of the whole antenna is wider than that of the hybrid feeding network because the coupling among the $\Gamma$ shape strips may cause additional cancellation, and the resistances of $\Gamma$ shape strips are varied with different frequencies, especially at the edge of the passband, while the hybrid ring feeding network is designed with Ports 3-6 whose characteristic impedance is $50 \Omega$. And there is no mutual coupling between Ports 3-6. 


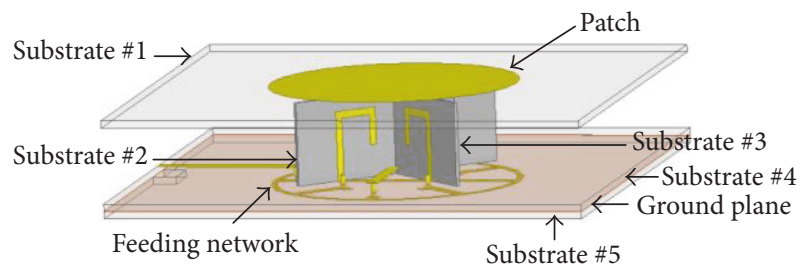

(a)

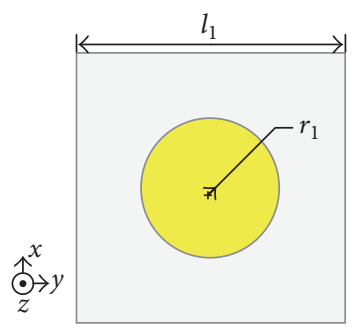

(b)

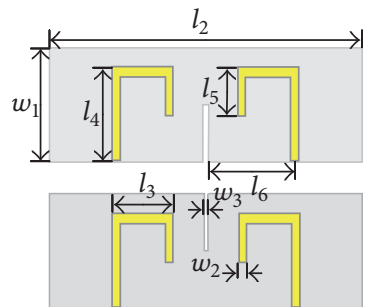

(c)

Figure 6: Geometry of the proposed antenna. (a) Perspective view of the antenna. (b) Structure of substrate \#1. (c) Structure of substrates $\# 2$ and \#3. $l_{1}=105 \mathrm{~mm}, l_{2}=50 \mathrm{~mm}, l_{3}=10 \mathrm{~mm}, l_{4}=15 \mathrm{~mm}, l_{5}=8 \mathrm{~mm}, l_{6}=13.9 \mathrm{~mm}, w_{1}=18 \mathrm{~mm}, w_{2}=1.5 \mathrm{~mm}, w_{3}=0.8 \mathrm{~mm}$, and $r_{1}=27 \mathrm{~mm}$.

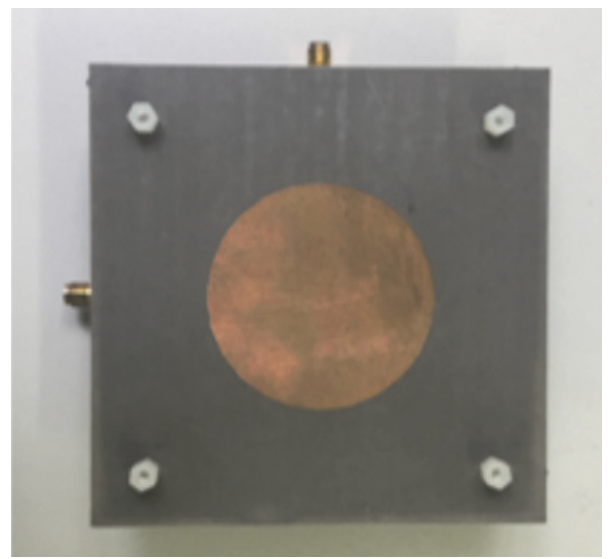

(a)

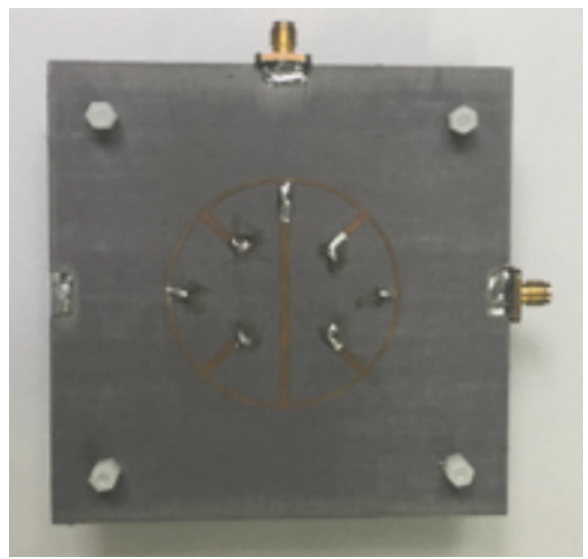

(b)

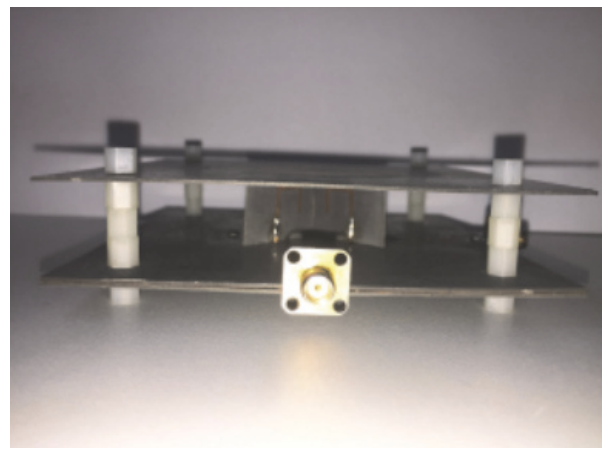

(c)

Figure 7: Photograph of the proposed antenna. (a) Top view. (b) Bottom view. (c) Side view.

Figure 9 shows the simulated and measured normalized $E$ plane and $H$-plane radiation patterns at $2.3 \mathrm{GHz}$ for Port 1 and Port 2 excitations. Note that while measuring the radiation patterns at one port, another port is terminated with a $50 \Omega$ load. Symmetric radiation patterns with low cross-polarization level are observed. The measured crosspolarization levels in both $E$-plane and $H$-plane are less than $24 \mathrm{~dB}$ at Port 1 and Port 2. The measured gains in the broadside direction for Ports 1 and 2 excitations at $2.3 \mathrm{GHz}$ are both about $9 \mathrm{dBi}$. A comparison of the proposed antenna with other dual-polarized patch antennas is listed in Table 1. It is shown that the proposed antenna has the merits of high port-to-port isolation in a wide operating band and low crosspolarization level.

\section{Conclusion}

A high isolation and wideband dual-polarized microstrip patch antenna fed by hybrid ring feeding network has been proposed in this paper. The hybrid ring feeding network has a fully symmetric structure and performance of high isolation within a wide bandwidth. The antenna shows wide operation bands, low cross-polarization level, high ports isolation, and 
TABLE 1: Comparison with previous works.

\begin{tabular}{lcccc}
\hline Ref. & Isolation $(\mathrm{dB})$ & Relative impedance bandwidth & Cross-polarization $(\mathrm{dB})$ & 20 \\
\hline$[7]$ & 28.5 & $18.8 \%$ & $h_{d}\left(\lambda_{0}\right)$ \\
{$[8]$} & 30 & $45.5 \%$ & 25 & 0.08 \\
{$[9]$} & 32 & $22.7 \%$ & 30 & 0.59 \\
{$[10]$} & 40 & $14 \%$ & 30 & 0.17 \\
{$[11]$} & 37 & $47 \%$ & NG & 0.08 \\
{$[12]$} & 30 & $41.7 \%$ & 20 & 0.184 \\
This work & 40 & $38.7 \%$ & 24 & 0.144 \\
\hline
\end{tabular}

$h_{d}\left(\lambda_{0}\right)$ : the overall height corresponds to $\lambda_{0}$.

NG: not given.

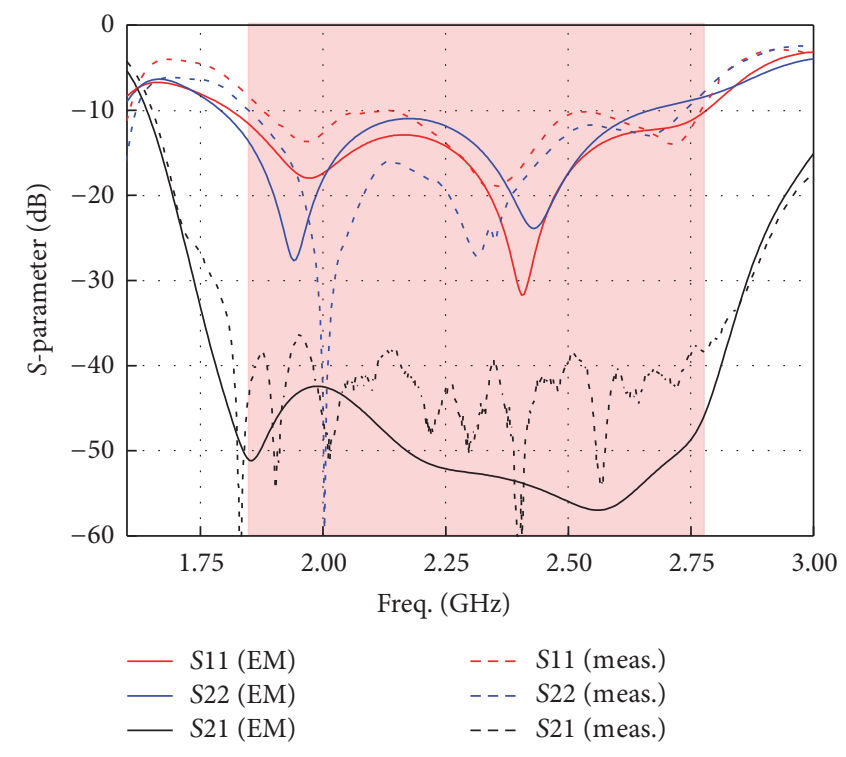

Figure 8: S-parameters of the proposed antenna.

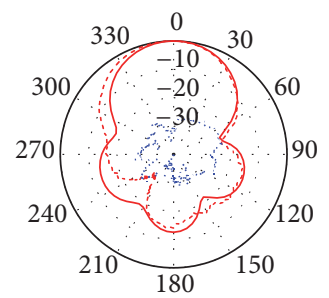

$x$ - $z$ plane $(E$-plane)

— Co-Pol (EM)
Cross-Pol (EM)

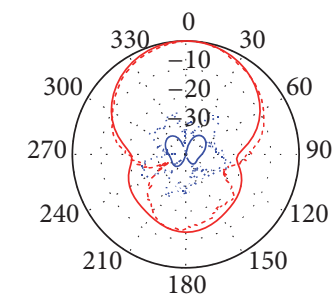

$y$ - $z$ plane (H-plane)

- - Co-Pol (meas.)

- - Cross-Pol (meas.)

(a)

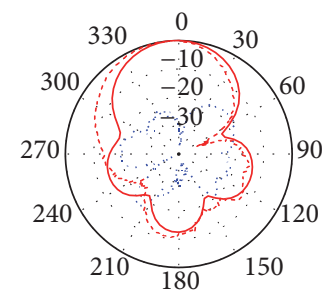

$x$ - $z$ plane (E-plane)

Co-Pol (EM)
- Cross-Pol (EM)

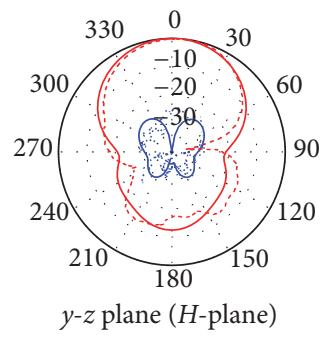

- - - Co-Pol (meas.)

- - Cross-Pol (meas.)

(b)

Figure 9: Measured and simulated normalized radiation patterns at $2.3 \mathrm{GHz}$ at (a) E-plane and $H$-plane for Port 1 and (b) E-plane and $H$-plane for Port 2. 
good gain. The hybrid ring feeding network can be readily used in other wideband dual-polarized antenna designs.

\section{Conflicts of Interest}

The authors declare that there are no conflicts of interest regarding the publication of this paper.

\section{Acknowledgments}

This work is supported by the National Natural Science Foundation of China (61571194).

\section{References}

[1] K.-L. Wong, H.-C. Tung, and T.-W. Chiou, "Broadband dualpolarized aperture-coupled patch antennas with modified $\mathrm{H}-$ shaped coupling slots," IEEE Transactions on Antennas and Propagation, vol. 50, no. 2, pp. 188-191, 2002.

[2] S. Gao, L. Li, M. Leong, and T. Yeo, "Dual-polarized slot-coupled planar antenna with wide bandwidth," IEEE Transactions on Antennas and Propagation, vol. 51, no. 3, pp. 441-448, 2003.

[3] K. Wei, Z. Zhang, W. Chen, and Z. Feng, "A novel hybrid-fed patch antenna with pattern diversity," IEEE Antennas and Wireless Propagation Letters, vol. 9, pp. 562-565, 2010.

[4] J.-J. Xie, Y.-Z. Yin, J.-H. Wang, and X.-L. Liu, "Wideband dualpolarised electromagneticfed patch antenna with high isolation and low cross-polarisation," Electronics Letters, vol. 49, no. 3, pp. 171-173, 2013.

[5] H.-W. Lai and K.-M. Luk, "Dual polarized patch antenna fed by meandering probes," IEEE Transactions on Antennas and Propagation, vol. 55, no. 9, pp. 2625-2627, 2007.

[6] H. Wong, K. L. Lau, and K. M. Luk, "Design of dual-polarized L-probe patch antenna arrays with high isolation," IEEE. Transactions on Antennas and Propagation, vol. 52, no. 1, pp. 45-52, 2004.

[7] Y. Cheng, Y. Li, and W. Lu, "A novel compact dual-polarized antenna," International Journal of Antennas and Propagation, vol. 2016, Article ID 6304356, 5 pages, 2016.

[8] Z. J. Yang, Y. C. Jiao, Z. B. Weng, and L. Zhou, "A compact broadband dual-polarized omnidirectional antenna with high isolations for indoor DAS application," Microwave and Optical Technology Letters, vol. 59, no. 1, pp. 176-180, 2017.

[9] S.-G. Zhou, P.-K. Tan, and T.-H. Chio, "Low-profile, wideband dual-polarized antenna with high isolation and low cross polarization," IEEE Antennas and Wireless Propagation Letters, vol. 11, pp. 1032-1035, 2012.

[10] C. Deng, Y. Li, Z. Zhang, and Z. Feng, "A wideband high-isolated dual-polarized patch antenna using two different balun feedings," IEEE Antennas and Wireless Propagation Letters, vol. 13, pp. 1617-1619, 2014.

[11] C.-Y. Sim, C.-C. Chang, and J.-S. Row, "Dual-feed dualpolarized patch antenna with low cross polarization and high isolation," IEEE Transactions on Antennas and Propagation, vol. 57, no. 10, pp. 3321-3324, 2009.

[12] K. M. Mak, X. Gao, and H. W. Lai, "Low cost dual polarized base station element for long term evolution," IEEE Transactions on Antennas and Propagation, vol. 62, no. 11, pp. 5861-5865, 2014.

[13] J. Zhang, X. Q. Lin, L. Y. Nie, J. W. Yu, and Y. Fan, "Wideband dual-polarization patch antenna array with parallel strip line balun feeding," IEEE Antennas and Wireless Propagation Letters, vol. 15, pp. 1499-1501, 2016. 


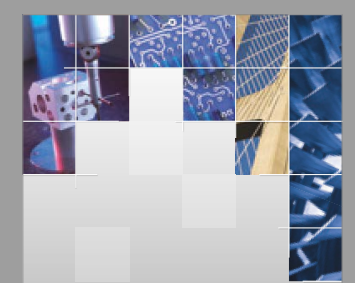

\section{Enfincering}
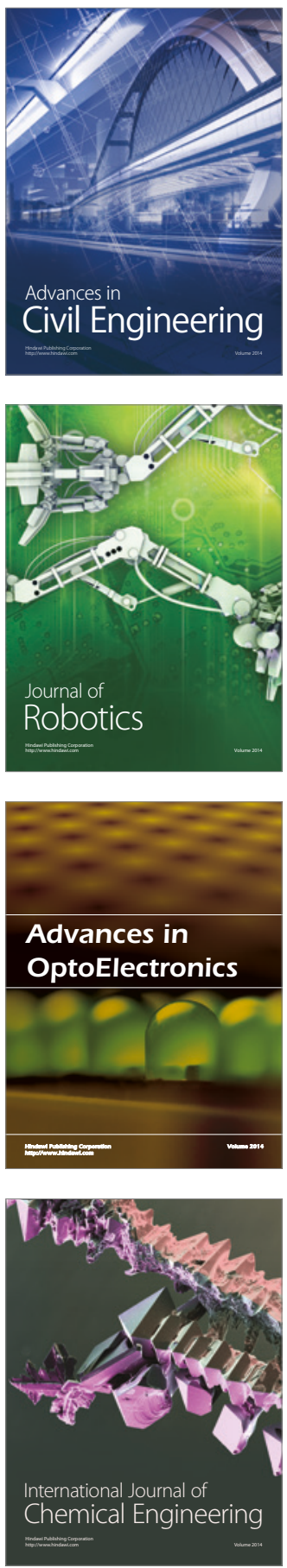

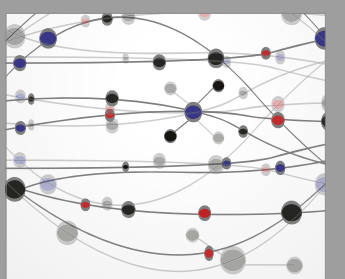

The Scientific World Journal

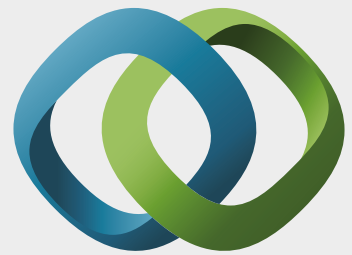

\section{Hindawi}

Submit your manuscripts at

https://www.hindawi.com
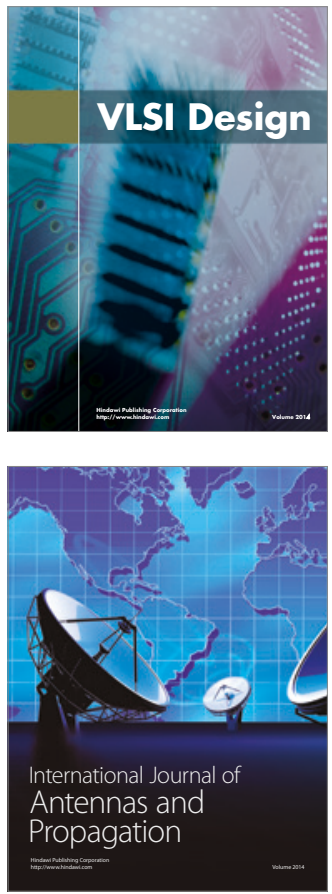

\section{Rotating}

Machinery
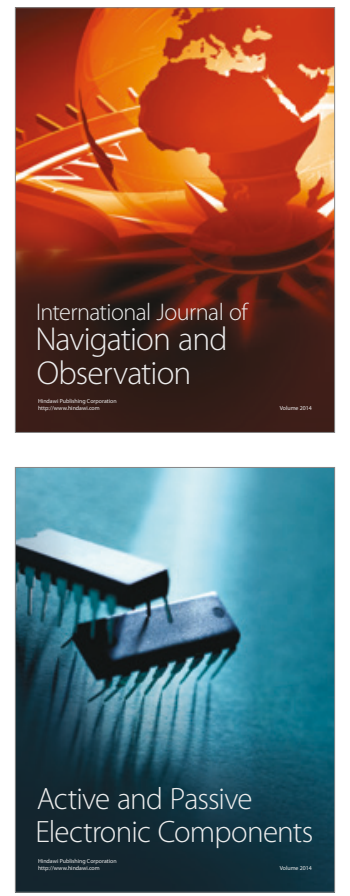
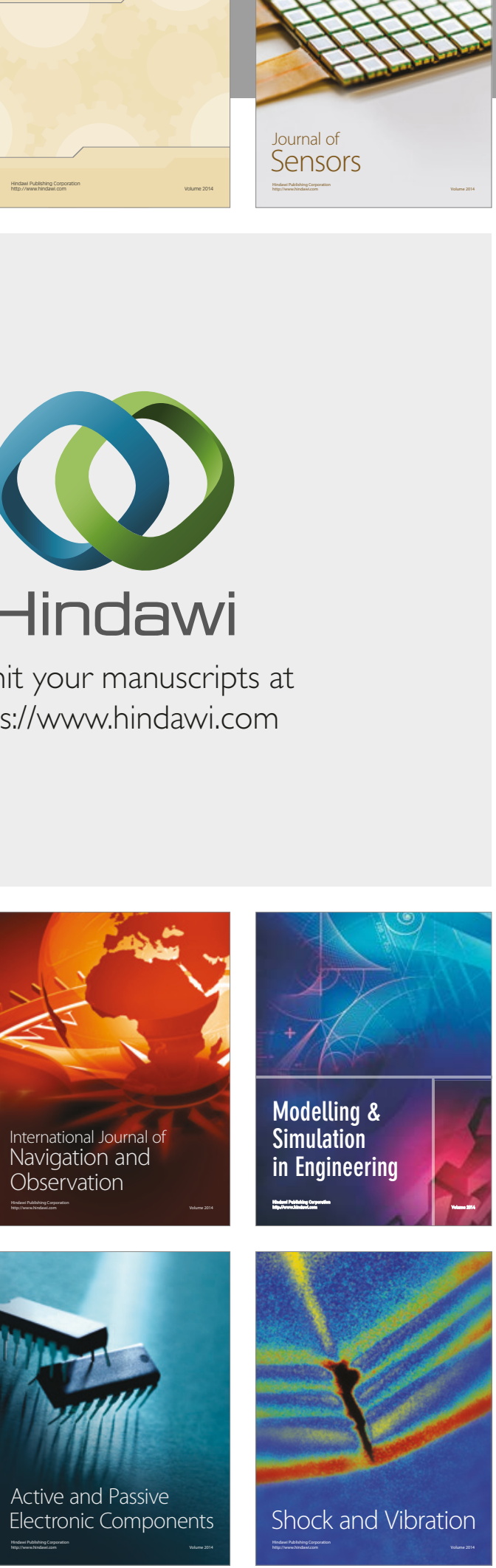
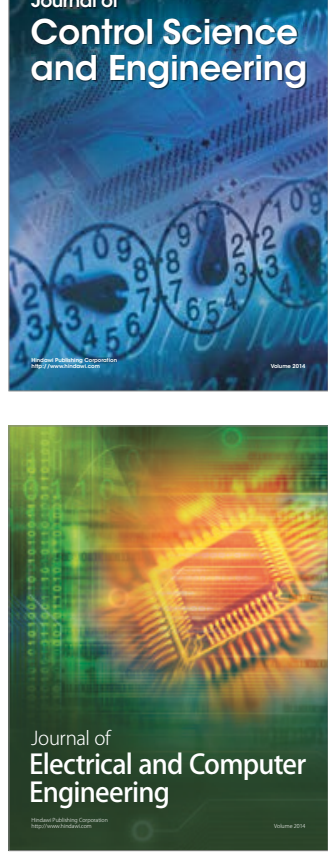

Distributed

Journal of

Control Science

and Engineering
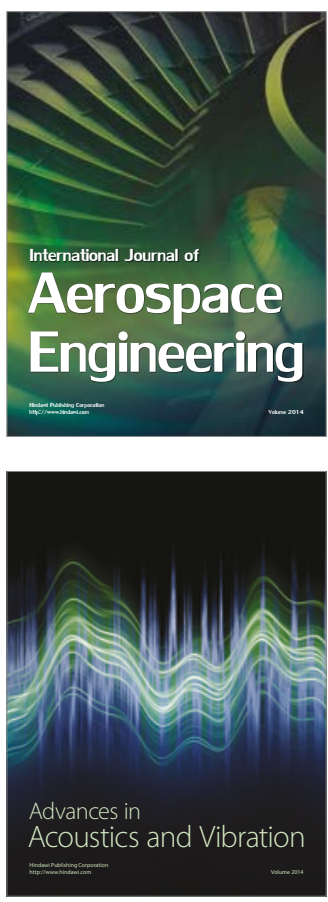

Sensor Networks 